\title{
Construction of perfectly continuous records of physical properties for dark-light sediment sequences collected from the Japan Sea during Integrated Ocean Drilling Program Expedition 346 and their potential utilities as paleoceanographic studies
}

Tomohisa Irino ${ }^{1 *}$ D, Ryuji Tada ${ }^{2}$, Ken Ikehara ${ }^{3}$, Takuya Sagawa ${ }^{4}$, Akinori Karasuda ${ }^{2}$, Shunsuke Kurokawa², Arisa Seki ${ }^{2}$ and Song Lu ${ }^{5}$

\begin{abstract}
Establishment of sedimentary sequence is essential for the interpretation of the sedimentary records. Integrated Ocean Drilling Program (IODP) Expedition (Exp.) 346 drilled high-quality sediment archives with more than three holes each at nine sites that enable us to establish continuous sedimentary sequences through splicing technique. After extensive efforts to replace the disturbed, missed, or duplicated intervals found in spliced sediment sequences constructed onboard during IODP Exp. 346 to the corresponding undisturbed intervals, nearly perfectly continuous sediment columns and physical property records for the Pleistocene intervals of Sites U1422-U1427 and U1430 collected from the Japan Sea have been established. Same kind of efforts to correct the shipboard splices were also achieved for Plio-Miocene intervals at Sites U1425 and U1430. The continuous records established for these sites will allow a much more detailed understanding of the long-term variability in East Asian paleoclimate and North Pacific oceanography.
\end{abstract}

Keywords: IODP Expedition 346, The Japan Sea, Hemipelagic sediment, Stratigraphy, Splice, Composite depth, Visual core description, Physical property, Dark-light cycles

\section{Introduction}

Establishment of a continuous sedimentary sequence is an unavoidable starting point for the interpretation of the sedimentary records as events in earth history (Doyle and Bennett 1998). Multi-hole drilling has been widely used by scientific drilling operations such as Ocean Drilling Program (ODP) and Integrated Ocean Drilling Program (IODP) that allow us to establish continuous sedimentary records through splicing fragmented intervals from top to bottom of the sequence (Ruddiman et al. 1987). Splicing is usually performed onboard using

\footnotetext{
* Correspondence: irino@ees.hokudai.ac.jp

${ }^{1}$ Faculty of Environmental Earth Science, Hokkaido University, N10-W5

Kita-ku, Sapporo 060-0810, Japan

Full list of author information is available at the end of the article
}

physical properties such as magnetic susceptibility (MS), gamma-ray attenuation (GRA) density, natural gammaray radiation (NGR), and the lightness and color of sediments measured immediately after drilling. These physical properties are compared between the drilled holes, and inter-hole correlations are recognized according to the fluctuation patterns of these properties.

Revisions of spliced sequences after the cruise have been also common for the high-resolution paleoceanographic researches, which were required for a precise orbital tuning and inter-site correlations. The splice for ODP Site 964 (Emeis et al. 1996) was fully reassessed using core photograph and shipboard color data and revised by Sakamoto et al. (1998). This revision was further modified by choosing better intervals in different 
holes (Lourens 2004). The original splice for ODP Site 982 (Jansen et al. 1996) was also revised by Khélifi et al. (2012) through inspection of magnetostratigraphic reversals and the addition of epibenthic $\delta^{18} \mathrm{O}$ records although Lawrence et al. (2013) recommended to return to the original splice based on the re-examination of a detailed shore-based magnetostratigraphy (Channell and Guyodo, 2004). Splices for IODP Expedition (Exp.) 320 (Lyle et al., 2009) were revised in the Expedition research results and summarized by Westerhold et al. (2012). Although these works gave their own revised splice interval tables that describe the stratigraphic positions of top and bottom of chosen splice intervals as well as offsets necessary for adjusting cores to the revised depth, it was not easy to find correspondence between the original depth scale and the revised one. In the case of ODP Site 1092 (Gersonde et al. 1999), the shipboard splice was revised using X-ray fluorescence (XRF) scanner data collected after the cruise to improve inter-hole correlation for intervals with too uniform physical properties (Evans et al. 2004). In this example, differences between the original composite depth and revised one were listed in the table that may be helpful for the calculation of the revised depth. In all the examples above, careful visual inspections of core images and/or higher resolution measurements of sediment properties were essential for greater improvement of splices.

IODP Exp. 346 also adopted multi-hole drilling where high-quality splicing of sedimentary sequences at each drilled site has been performed (Tada et al. 2015). The aims of this expedition were to test the hypothesis that Pliocene-Pleistocene uplift of the Himalaya and Tibetan Plateau and the consequent emergence of the two discrete modes of Westerly Jet circulation could have caused the amplification of millennial-scale variability of the East Asian summer monsoon and East Asian winter monsoon, which could also provide teleconnection mechanisms for Dansgaard-Oeschger cycles. Multiple time scales were targeted to reconstruct the onset and evolution of orbital- and millennial-scale variations of summer and winter monsoons, Westerly Jet position and intensity, desertification in East and Central Asia, and their interrelationships since the middle Miocene. In order to accomplish these initial purposes of this expedition, establishment of sediment record as continuous as possible at each site was strongly required. Such continuous sediment records were also necessary to conduct precise inter-site stratigraphic correlations in millennial to orbital time scales to reconstruct spatio-temporal variability of paleoceanographic and paleoclimatic conditions in this region (Tada et al. 2018).

Since the splicing of cores collected during Exp. 346 was conducted by the correlations of physical properties among the drilled holes, minor sediment disturbance that can be only recognized by a careful visual inspection would be missed. In order to establish a more complete and continuous spliced section and profiles of physical properties of sediment core, we tried to identify minor disturbed, missing, or overlapped intervals unconsciously involved in the spliced sequences and replace such intervals with the corresponding undisturbed intervals from another hole. We have also taken care of traceability of processes of stratigraphic revisions to keep compatibility between the newly revised depth scale and the original one. Accomplishment of these tasks enabled the research community to access, examine, and utilize our revised stratigraphic frameworks for the most of the sediment cores collected in the Japan Sea during this expedition.

\section{Materials and data \\ Drilled sites}

The Japan Sea is a marginal sea located at the eastern edge of the far-east Asia (Fig. 1). The sea is connected to the outside through the Tsushima, Tsugaru, Soya, and Mamiya Straits from south to north. The Tsushima Warm Current (TWC) is an only ocean current flowing into the Japan Sea from the outside in modern times. TWC water flows out of the sea mostly from the Tsugaru Strait, and the remaining water flows further north to the Soya Strait (Hase et al. 1999). Salinity and nutrient in the TWC is controlled by the circulation in the East China Sea and the Yangtze discharge which could be controlled by precipitation over South China during the East Asian summer monsoon season. The deep water circulation in the Japan Sea is characterized by intense ventilation due to severe cooling during winter monsoon season, which promotes the hyper-oxic deep water condition and shallow carbonate compensation depth of the sea (Gamo et al. 2014). The Japan Sea is also located at downwind of the Asian dust sources and receives a significant amount of dust transported by westerlies in spring or northwestern monsoon wind in winter (Irino and Tada 2000, 2002). Therefore, the reconstructions of the spatio-temporal variation for fluxes of organic and carbonate carbon, bottom water redox condition, and dust from sediment archives in the Japan Sea are essential to understand the past variability of the East Asian summer and winter monsoon as well as the strength and latitudinal position of westerlies since the middle Miocene (Tada et al. 2015).

We tried to revise the original spliced sequences constructed at seven sites drilled during Exp. 346 such as Sites U1422-U1427 and U1430 (Fig. 1). Sediments mainly consist of silty clay to clayey silt with various amounts of biogenic silica and minor carbonate (Tada et al. 2015). Sites U1422-U1426 and U1430 are located at bathyal depths and characterized by decimeter to meter scale dark-light bandings which correspond to Dansgaard-Oeschger cycles 


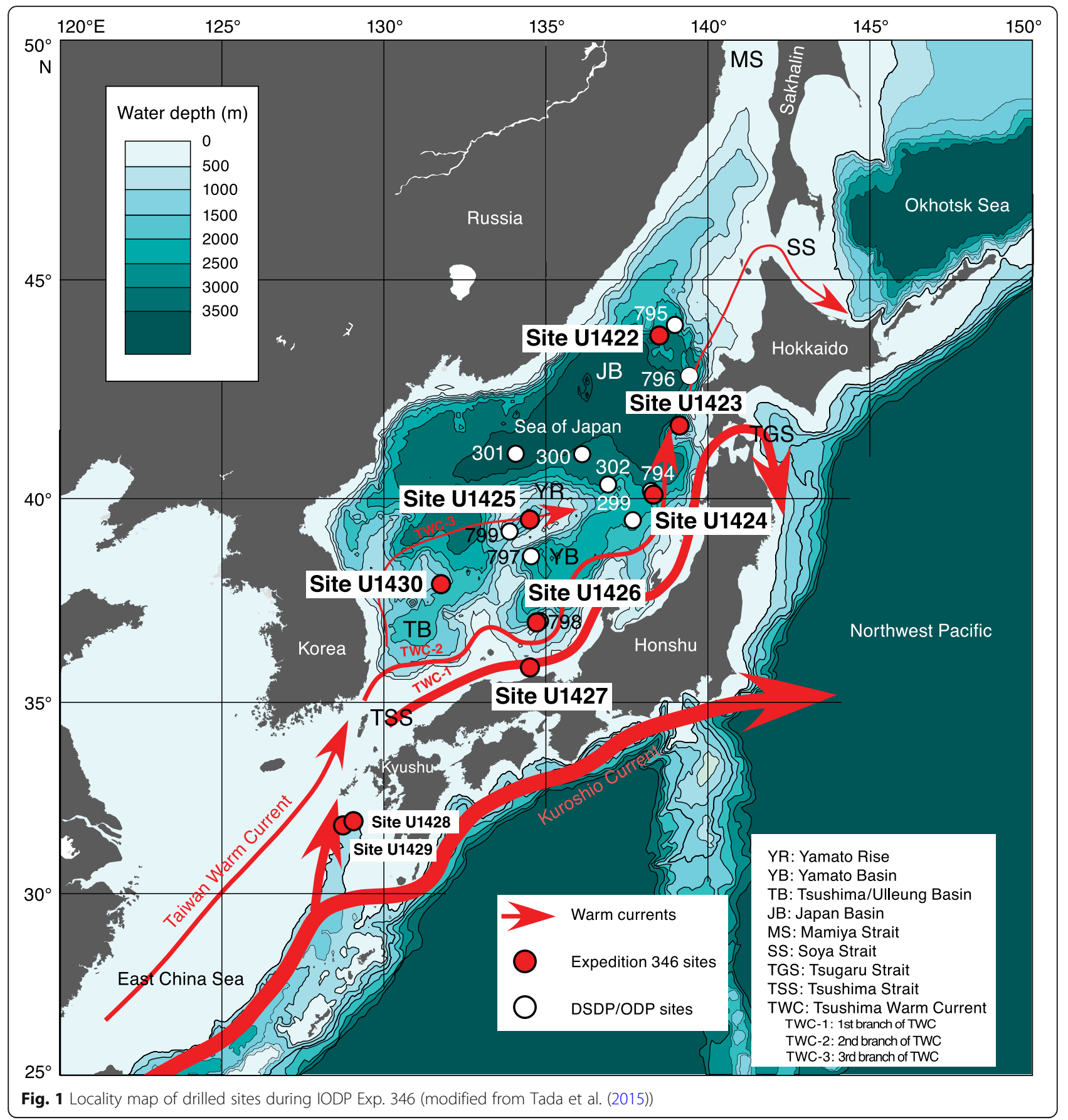

(Tada et al. 1999), while Site U1427 is located at the upper slope and its sediments consist of homogenous or bioturbated clayey silt (Fig. 1). Water depths are, in ascending order, $330 \mathrm{~m}$ at Site U1427, $903 \mathrm{~m}$ at Site U1426, $1072 \mathrm{~m}$ at Site U1430, $1785 \mathrm{~m}$ at Site U1423, $1909 \mathrm{~m}$ at Site U1425, $2808 \mathrm{~m}$ at Site U1424, and $3429 \mathrm{~m}$ at Site U1422 (Tada et al. 2015). Therefore, an appropriate combination of these cores could provide a suitable set of depth transect to reconstruct the depth gradient of biogenic fluxes and deep water ventilation in the past.

\section{Collected data}

Depth information and physical property data collected during Exp. 346 and used in this study are all downloadable from the Laboratory Information Management System (LIMS) database (http://web.iodp.tamu.edu/LORE/). Depth scales used during the cruise were called CSF-A, CCSF-A, and CCSF-D. CSF-A is the depth (m) drilled from the sea floor regardless of potential gaps and overlaps between cores. Since more than one hole were drilled at one site during Exp. 346, the core gaps recognized at 
one hole could be fulfilled with the corresponding interval found at the other hole. In order to fill the core gap, offset values were added to the original drilled depth (CSF-A) of each core as to align the correlated horizons at the same depth, and then, a composite depth scale (CCSF-A) was defined for each core. The list of the offset values for adjustment of each core was called "affine table" which was also downloadable from LIMS database. A single continuous sediment sequence was constructed by splicing continuous intervals chosen from the multi-hole sequences, whose depth scale was called CCSF-D. The term CCSF-D is only used for splice and is same as CCSF-A for the intervals involved in the splice.

Physical properties utilized to establish composite depth scale at each site were MS, GRA density, NGR as well as red-green-blue (RGB) channel values extracted from digital images and reflectance spectroscopy and colorimetry (RSC). During Exp. 346, measurement intervals were routinely set as $2.5 \mathrm{~cm}$ for MS and GRA, $20 \mathrm{~cm}$ for NGR, and $1 \mathrm{~cm}$ for RSC. RSC was not measured for holes U1425E and U1427C due to time limitations. RGB values were routinely extracted onboard for every $5 \mathrm{~mm}$ interval and uploaded to LIMS database. These RGB values extracted onboard were different from those recorded in digital image of each section due to encoding procedure (Ebner 2007). Cores U1424C-1H through $3 \mathrm{H}$ and $\mathrm{U} 1425 \mathrm{C}-1 \mathrm{H}$ through $3 \mathrm{H}$ which were recovered for optically stimulated luminescence (OSL) sampling in the dark further required collection of MS, GRA, photographs (RGB), and RSC later in the Kochi Core Center (KCC). NGR was not measured for these cores (Tada et al. 2015).

\section{Methods/experimental}

\section{Strategy}

The strategy here was to establish continuous sedimentary records for lithological subunits IA and IB intervals which were characterized by clear dark-light color banding at Sites U1422-U1426 and U1430 (Tada et al. 2015). We have also made same efforts for the intervals below $110 \mathrm{~m}$ CCSF-D of Site U1425, below $80 \mathrm{~m}$ CCSF-D of Site U1430, and 0 to $440 \mathrm{~m}$ CCSF-D of Site U1427 where banded stratifications were not necessarily clear, in order to establish precise age models for the Mio-Pliocene intervals at Sites U1425 and U1430 and for the whole spliced intervals at Site U1427 at a shallower water depth (Sagawa et al. 2018). As a result, we have worked out for revised stratigraphy down to $100 \mathrm{~m}$ CCSF-D for U1422, $140 \mathrm{~m}$ CCSF-D for U1423, $100 \mathrm{~m}$ CCSF-D for U1424, $350 \mathrm{~m}$ CCSF-D for U1425, $235 \mathrm{~m}$ CCSF-D for U1426, $440 \mathrm{~m}$ CCSF-D for U1427, and $260 \mathrm{~m}$ CCSF-D for U1430.

In this study, we aim to keep the correspondence between the original shipboard splice depth (m CCSF-D) and the newly revised splice depth scale compatible. The revised stratigraphic positions should be easily recognized, and the conversion from the revised depth scale to the shipboard original depth scale should be possible for everyone. In order to realize this policy, the workflow consisting of four steps is as follows:

1. Align all the core/section photographs in a same scale based on the affine table,

2. Identify disturbed or missing intervals involved in the spliced section,

3. Find the corresponding undisturbed intervals from another hole as the alternative "patch," and

4. Replace the disturbed or missing interval with this "patch,"

through careful inspections of core-section photographs available from IODP LIMS database. When aligning and connecting core-section photographs, the section widths were expanded and brightness and contrast were adjusted to easily recognize the sediment qualities such as lithology, stratification, and disturbance on the sediment split surface (Additional file 1: Figure S1; Additional file 2: Figure S2; Additional file 3: Figure S3; Additional file 4: Figure S4; Additional file 5: Figure S5; Additional file 6: Figure S6; Additional file 7: Figure S7).

On the inter-hole correlation photographs in Additional file 1: Figure S1, Additional file 2: Figure S2, Additional file 3: Figure S3, Additional file 4: Figure S4, Additional file 5: Figure S5; Additional file 6: Figure S6, and Additional file 7: Figure S7, originally spliced intervals are indicated by blue lines next to core photographs. Disturbed or missing intervals found at step 2 are indicated by blue broken lines. These disturbed or missing intervals were amended by the corresponding undisturbed "patch" intervals indicated by pink lines.

The top and bottom depth of disturbed intervals found at step 2 and "patch" intervals chosen at step 3 were defined in the precision of $\pm 5 \mathrm{~mm}$. The correspondence between the disturbed intervals and the "patch" intervals are summarized as tables for patched intervals (Additional file 8). Patching may change the original composite depth (m CCSF-D) due to the difference of thickness between the disturbed and patch intervals. Therefore, the newly revised depth scale was defined as m CCSF-D_Patched_revYYYY MMDD where YYYYMMDD was the final date of the revision (Additional file 8). We also provide the revised splice interval table for each site (Additional file 9) defined as the patched sequence.

\section{Patching physical properties data}

Construction of the patched stratigraphic column resulted in the changes of depth values from the original splice "CCSF-D." The new "CCSF-D_Patched revYYYYMMDD" should be also applied to the spliced 
records of physical properties such as MS, GRA, NGR, $\mathrm{RGB}$, and RSC in order to obtain their nearly complete depth profiles. For this purpose, we conducted the following:

1. Translation of the splice (CCSF-D) depth-scale to the "CCSF-D_Pathced_revYYYYMMDD" depth-scale for each physical property data.

2. Replacement of the physical property data in disturbed intervals with those from the undisturbed patch intervals

3. Removal of outliers due to tephra, locally concentrated pyrites, or core disturbance such as core breaks, cracks, and styrofoam.

Then, we obtained a "patched and cleaned" profiles of physical properties that are provided in Additional file 10: Table S1, Additional file 11: Table S2, Additional file 12: Table S3, Additional file 13: Table S4; Additional file 14: Table S5, Additional file 15: Table S6, and Additional file 16: Table S7, and the examples using RGB profile are shown in Fig. 2a and b, Fig $2 c$ and d, Fig 2e and $f$ with "patched" sediment columns.

\section{Compatibility of photographic RGB and RSC data}

Color and brightness of the Japan Sea sediment has been treated as an essential property because the dark-light color cycles have been well-correlated basinwide (Tada 1994). Therefore, establishing completely continuous color profiles is essential for correlating between drill sites in the Japan Sea (Tada et al. 2018). When color data collected from core-sections such as photographic RGB values and RSC ( $\mathrm{L}^{*}, \mathrm{a}^{*}, \mathrm{~b}^{*}$, and tristimulus XYZ values) in disturbed intervals are patched by the data from another hole, it turned out that we need proper intercalibrations among RGB values collected onboard, RSC data, and RGB values extracted from section images on LIMS. Sections subjected to OSL sampling in the dark further required collection of physical properties and color data later in the KCC (Tada et al. 2015). Therefore, additional calibrations were also necessary to use the data for RGB and RSC taken from Cores U1424C-1H, $2 \mathrm{H}$, and $3 \mathrm{H}$ and $\mathrm{U} 1425 \mathrm{C}-1 \mathrm{H}, 2 \mathrm{H}$, and $3 \mathrm{H}$. Intercalibration between RGB and RSC is also necessary for holes U1425E and U1427C which were additionally drilled at the last moment of Exp. 346, and RSC data were not measured due to time limitations (Tada et al. 2015). Therefore, some special remarks related to color data handlings are described below.

\section{Depth adjustment for U1424B-2H-2 RGB data}

The assigned depth scale of RGB value for Section U1424B-2H-2 is $6.5 \mathrm{~cm}$ shallower in LIMS database because the top $6.5 \mathrm{~cm}$ interval of this section was not included in the cropped digital image due to an error during the operation. Therefore, we added $0.065 \mathrm{~m}$ to the depth of RGB values for Section U1424B-2H-2. The missing data could be fulfilled with RGB values extracted from the top $6.5 \mathrm{~cm}$ interval of the uncropped digital images stored in LIMS database.

\section{Inter-calibration among RGB values, RSC data, and digital images collected onboard}

RSC data on LIMS database include tristimulus $X, Y$, and $Z$ that are used to calculate $L^{*}, a^{*}$, and $b^{*}$. Interrelationship between tristimulus XYZ and RGB (defined from 0 to 100) is defined under D65 illuminant and $2^{\circ}$ observer:

$$
\begin{aligned}
& R=3.2404542 \mathrm{X}-1.5371385 \mathrm{Y}-0.4985314 \mathrm{Z} \\
& G=-0.9692660 \mathrm{X}+1.8760108 \mathrm{Y}+0.0415560 \mathrm{Z} \\
& B=0.0556434 \mathrm{X}-0.2040259 \mathrm{Y}+1.0572252 \mathrm{Z}
\end{aligned}
$$

which means $R=G=B=100$ when $X=95.047, Y=100$, and $Z=108.883$ where D65 illuminant is reflected on a perfect white (International Electrotechnical Commission, 1999). These "true" RGB (linear for our eyes) are encoded in color digital photograph as its own RGB color space such as $\mathrm{RRGB}$ in the jpeg section images on LIMS.

Let the encoded RGB values calculated from raw digital images on D/V JOIDES Resolution as $R_{J R}, G_{J R}$, and $B_{J R}$ and those extracted from the jpeg section images on LIMS as $R_{\text {photo }}, G_{\text {photo }}$, and $B_{\text {photo, }}$ where these encoded RGB are defined from 0 to 255 (8 bit). Transformations between "true" RGB and these encoded RGBs can be conducted with equations:

$$
\begin{aligned}
\frac{R}{100} & =\left(\frac{R_{J R}}{255}\right)^{\gamma_{R}^{I R}} \\
\frac{G}{100} & =\left(\frac{G_{J R}}{255}\right)^{\gamma_{G}^{I R}} \\
\frac{B}{100} & =\left(\frac{B_{J R}}{255}\right)^{\gamma_{B}^{I R}}
\end{aligned}
$$

and

$$
\begin{aligned}
\frac{R}{100} & =\left(\frac{R_{\text {photo }}}{255}\right)^{\gamma_{R}^{\text {photo }}} \\
\frac{G}{100} & =\left(\frac{G_{\text {photo }}}{255}\right)^{\gamma_{G}^{\text {photo }}} \\
\frac{B}{100} & =\left(\frac{B_{\text {photo }}}{255}\right)^{\gamma_{B}^{\text {photo }}}
\end{aligned}
$$




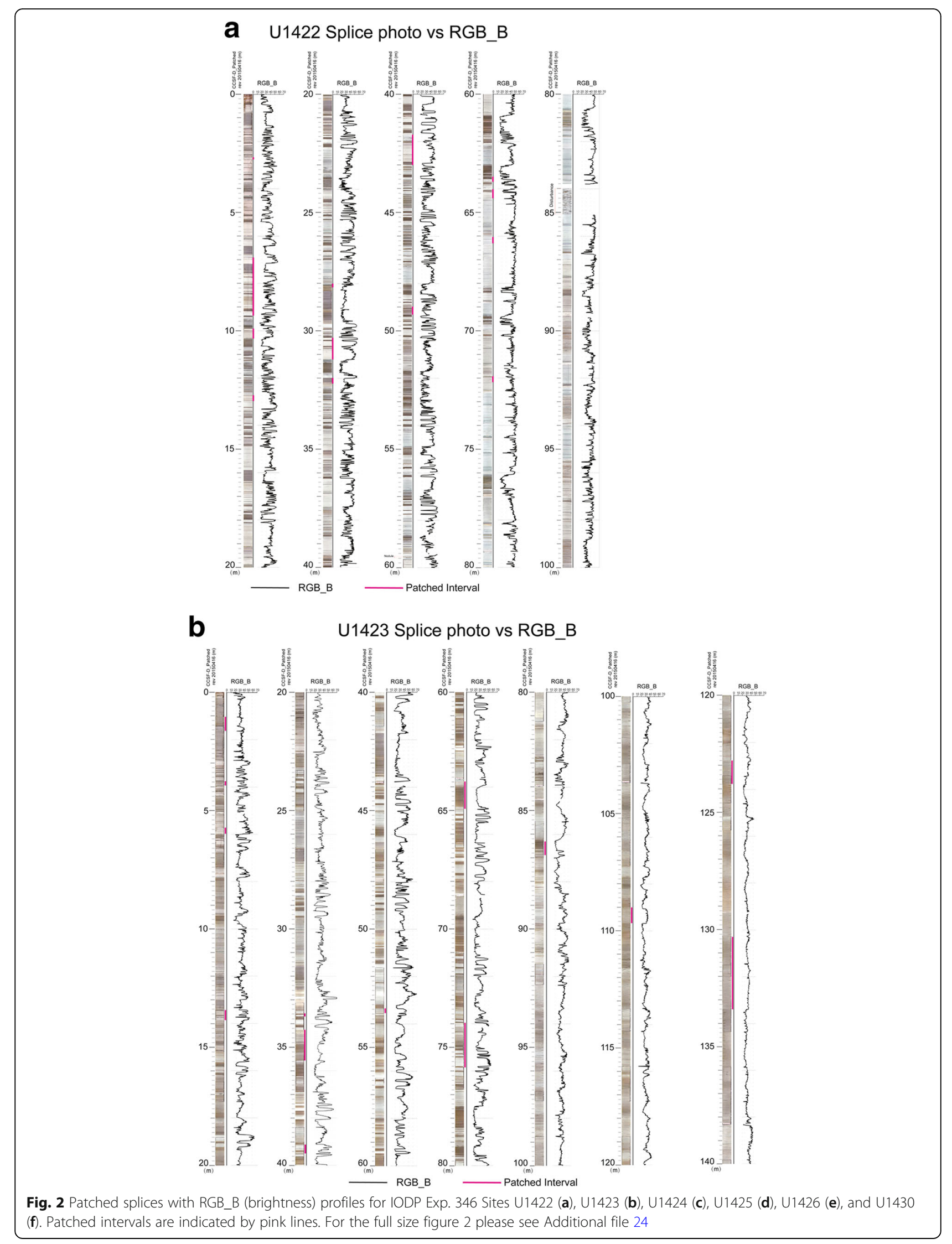




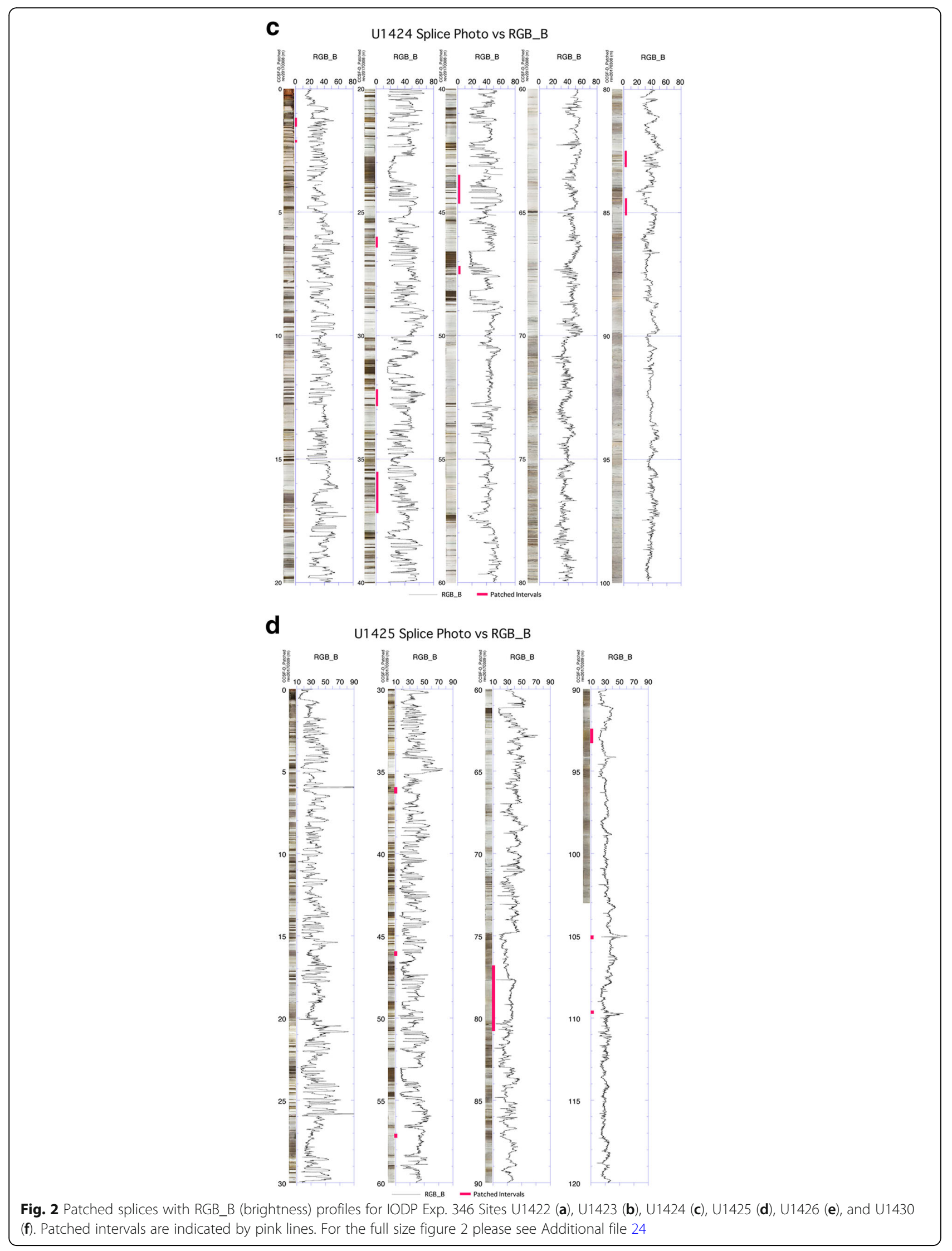




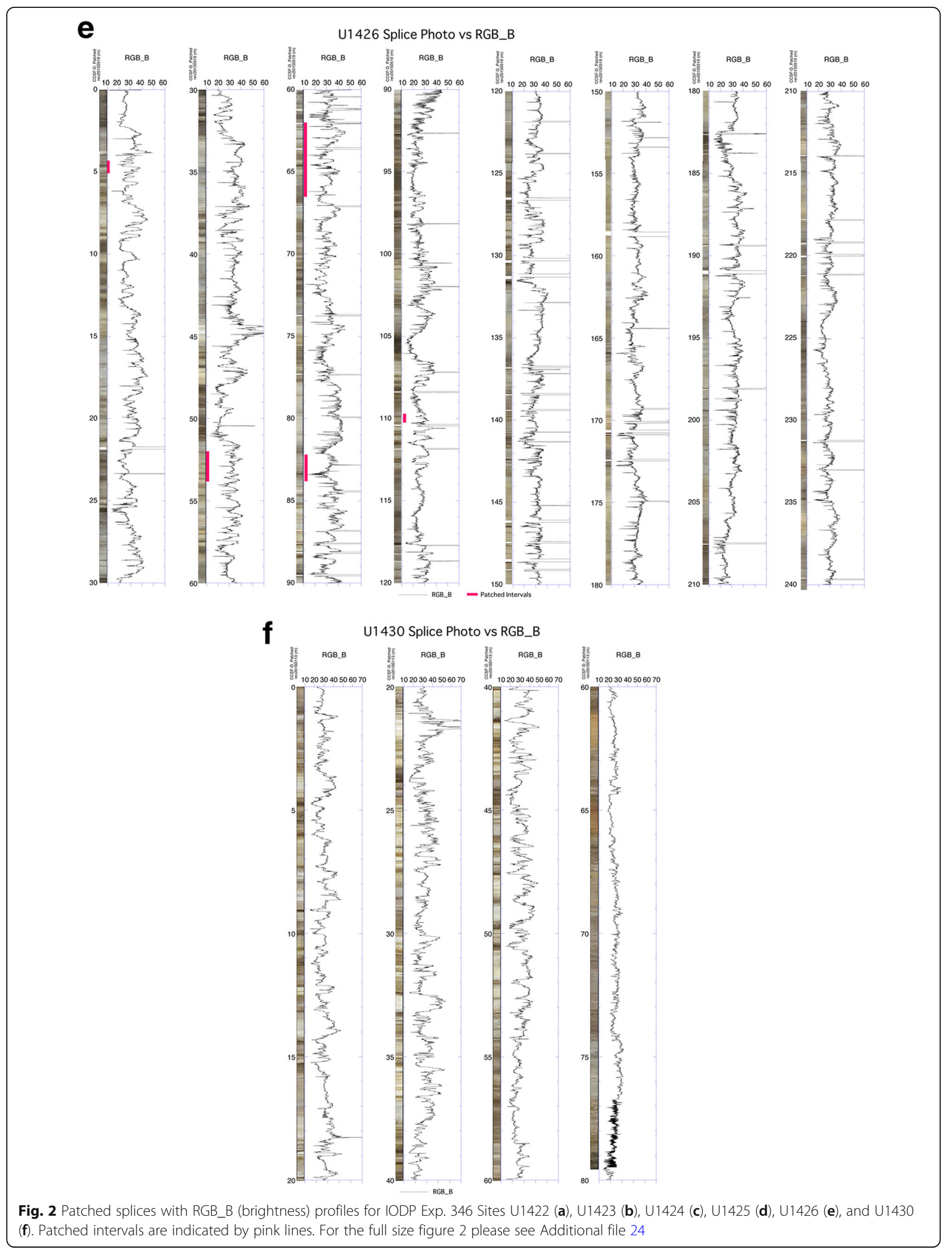


where power terms $\gamma$ are known as decoding gamma values (Ebner 2007). In the case that we could control the condition of data collection such as illumination and surface condition of sediments for digital image scanning and RSC measurement, these gamma values could be calibrated and defined well before data collection. However, actual scanning and measurement conditions were not consistent because of difference in illumination and use of GladWrap ${ }^{\mathrm{Tm}}$ for RSC, and therefore, these decoding gamma values have to be estimated through direct comparisons between "true" RGB and the encoded RGB using actual data.

In order to determine practical gamma values, we chose the Core U1424A-1H and compared the RGB calculated from the tristimulus XYZ to the encoded RGB values taken onboard and extracted from the jpeg section images. Figure 3 shows the relationships between the RGB calculated from the tristimulus $\mathrm{XYZ}$ and the encoded RGB from digital images. Power function fitting could determine practical gamma values as

$$
\gamma_{R}^{J R}=1.2961, \gamma_{G}^{J R}=1.3107, \gamma_{B}^{J R}=1.3320
$$

for the RGB collected onboard, and

$$
\gamma_{R}^{\text {photo }}=1.7748, \gamma_{G}^{\text {photo }}=1.7815, \gamma_{B}^{\text {photo }}=1.8146
$$

for the RGB extracted from the jpeg section images.

Since the tristimulus $X Y Z$ can be calculated from "true" RGB using equations

$$
\begin{aligned}
X & =0.4124564 \mathrm{R}+0.3575761 \mathrm{G}+0.1804375 \mathrm{~B} \\
Y & =0.2126729 \mathrm{R}+0.7151522 \mathrm{G}+0.0721750 \mathrm{~B} \\
Z & =0.0193339 \mathrm{R}+0.1191920 \mathrm{G}+0.9503041 \mathrm{~B}
\end{aligned}
$$

we could transform the encoded RGB to XYZ using gamma values determined above. Under D65 illuminant and $2^{\circ}$ observer conditions, $\mathrm{L}^{*}, \mathrm{a}^{*}$, and $\mathrm{b}^{*}$ are defined as (CIE, 2004)

$$
\begin{gathered}
\mathrm{L} *=116 \mathrm{Y}^{\prime}-16, \mathrm{Y}^{\prime}=\left\{\begin{array}{c}
\left(\frac{Y}{100}\right)^{\frac{1}{3}}\left(\frac{Y}{100}>0.008856\right) \\
7.787\left(\frac{Y}{100}\right)+\frac{16}{116}\left(\frac{Y}{100} \leq 0.008856\right)
\end{array}\right. \\
\mathrm{a} *=500\left(\mathrm{X}^{\prime}-Y^{\prime}\right), \mathrm{X}^{\prime}=\left\{\begin{array}{c}
\left(\frac{X}{95.047}\right)^{\frac{1}{3}}\left(\frac{X}{95.047}>0.008856\right) \\
7.787\left(\frac{X}{95.047}\right)+\frac{16}{116}\left(\frac{X}{95.047} \leq 0.008856\right)
\end{array}\right. \\
\mathrm{b} *=200\left(\mathrm{Y}^{\prime}-\mathrm{Z}^{\prime}\right), \mathrm{Z}^{\prime}=\left\{\begin{array}{c}
\left(\frac{Z}{108.883}\right)^{\frac{1}{3}}\left(\frac{Z}{108.883}>0.008856\right) \\
7.787\left(\frac{Z}{108.883}\right)+\frac{16}{116}\left(\frac{Z}{108.883} \leq 0.008856\right)
\end{array}\right.
\end{gathered}
$$

Then, we can inter-calibrate among RGB values collected onboard, RSC, and digital images.
In Fig. 4, blue and orange lines indicate the calculated $L^{*}$, $a^{*}$, and $b^{*}$ from RGB taken onboard and extracted from the jpeg section images, respectively, and are compared with the measured RSC data (red dots). The three datasets agree well with one another. RGB and RSC data for lost or disturbed intervals could be amended or replaced using the RGB extracted from the jpeg section images for the corresponding intervals.

For the top $6.5 \mathrm{~cm}$ of Section U1424B-2H-2 where digital image was miscropped and RGB was missed, we calculated the RGB values equivalent to those collected onboard using the RGB extracted from the jpeg digital image of this section. For the top $8 \mathrm{~cm}$ of Section U1424B-2H-3, a light-colored sediment penetrated into a dark layer at the center of the core due to disturbance and the onboard RGB data were collected on the light color portion (not on the proper dark portion) because the data were routinely taken from the center of the core (shown as dotted lines in Fig. 5). Therefore, we extracted the RGB values from proper dark portion of this interval using the jpeg image, calculated the RGB values equivalent to those taken onboard by the gamma corrections described above (solid lines in Fig. 5), and replaced the data. $\mathrm{L}^{*}$, $a^{*}$, and $b^{*}$ were replaced with those calculated from the jpeg extracted RGB at the proper dark portion as shown in Fig. 5 where $L^{*}$ was reasonably low for the dark layer in the top $8 \mathrm{~cm}$ interval.

\section{Inter-calibration of RGB values and RSC data between JOIDES Resolution (JR) and KCC}

For the patched interval from 1.22 to 1.53 m CCSF-D, the corresponding interval from the Core U1424C-1H was used to amend the data. Since physical properties for Cores $\mathrm{U} 1424 \mathrm{C}-1 \mathrm{H}, 2 \mathrm{H}$, and $3 \mathrm{H}$ were measured at KCC after Exp. 346, the RGB values were extracted from the digital images taken by the core scanner at KCC, and $\mathrm{L}^{*}, \mathrm{a}^{*}$, and $\mathrm{b}^{*}$ (and tristimulus $\mathrm{XYZ}$ ) values were transformed from those measured by the spectrophotometer used at KCC. In order to establish intercalibration between data taken onboard at JR and those from KCC, we first construct peak by peak matching between $\mathrm{B}$ splice profile and $\mathrm{B}$ values extracted from digital images of Cores $\mathrm{U} 1424 \mathrm{C}-1 \mathrm{H}, 2 \mathrm{H}$, and $3 \mathrm{H}$ as shown in Fig. 6. Then, RGB and XYZ data for corresponding stratigraphic positions were compared between the splice data taken onboard and U1424C data taken at KCC (Fig. 7). Figure $7 a-c$ shows that $R G B_{J R}$ do not converge to zero when $\mathrm{RGB}_{\mathrm{KCC}}$ get close to zero. This is probably due to the difference in sensitivity of scanners under very dark condition. Therefore, the transformation of RGB data from $\mathrm{KCC}$ values to JR ones requires the form of power function with bias factors $a$ as 

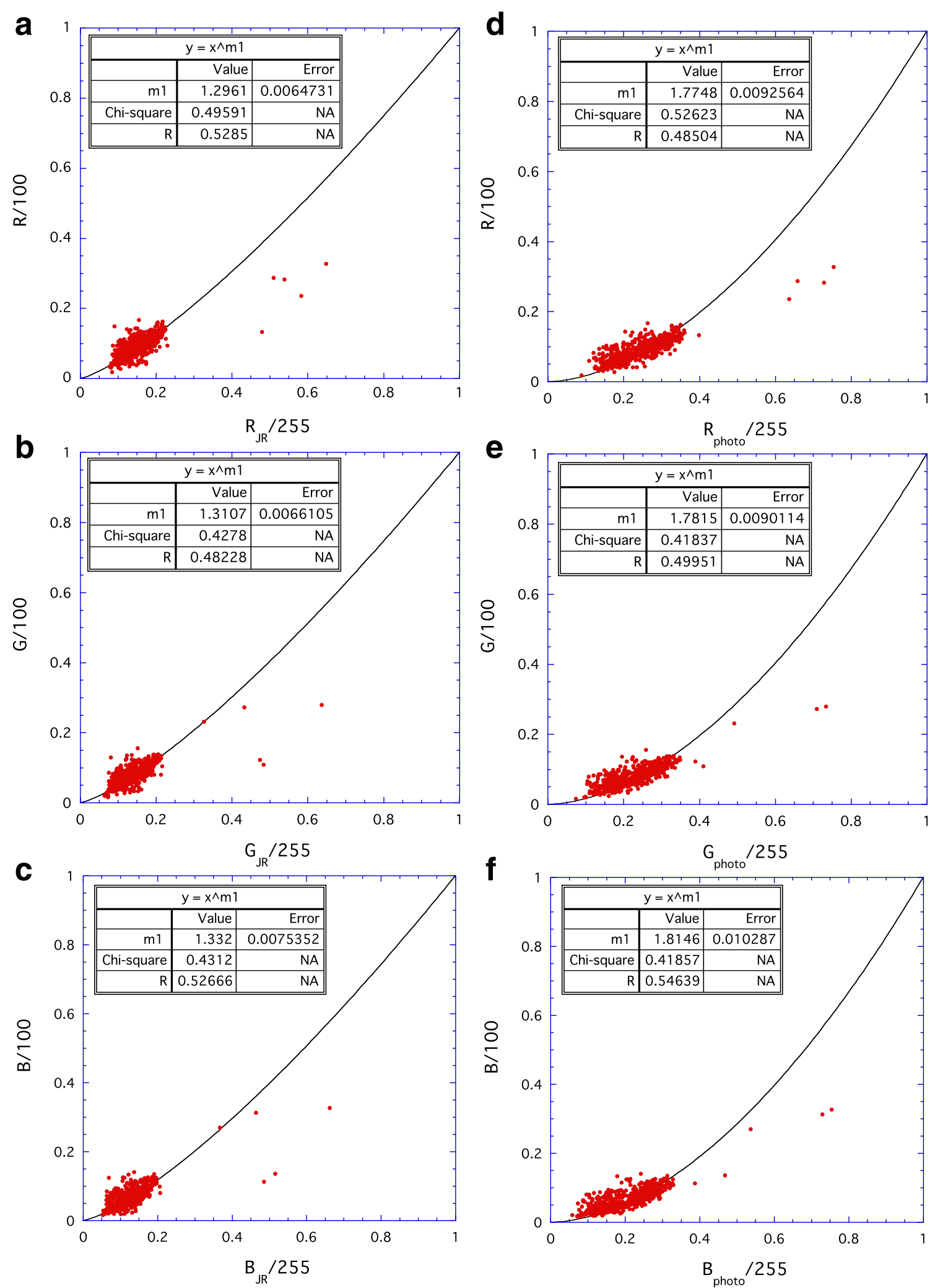

Fig. 3 Relationships between linear RGB estimated from RSC measurements and shipboard R (a), G (b), and B (c) or photo R (d), G (e), and $B(f)$ 


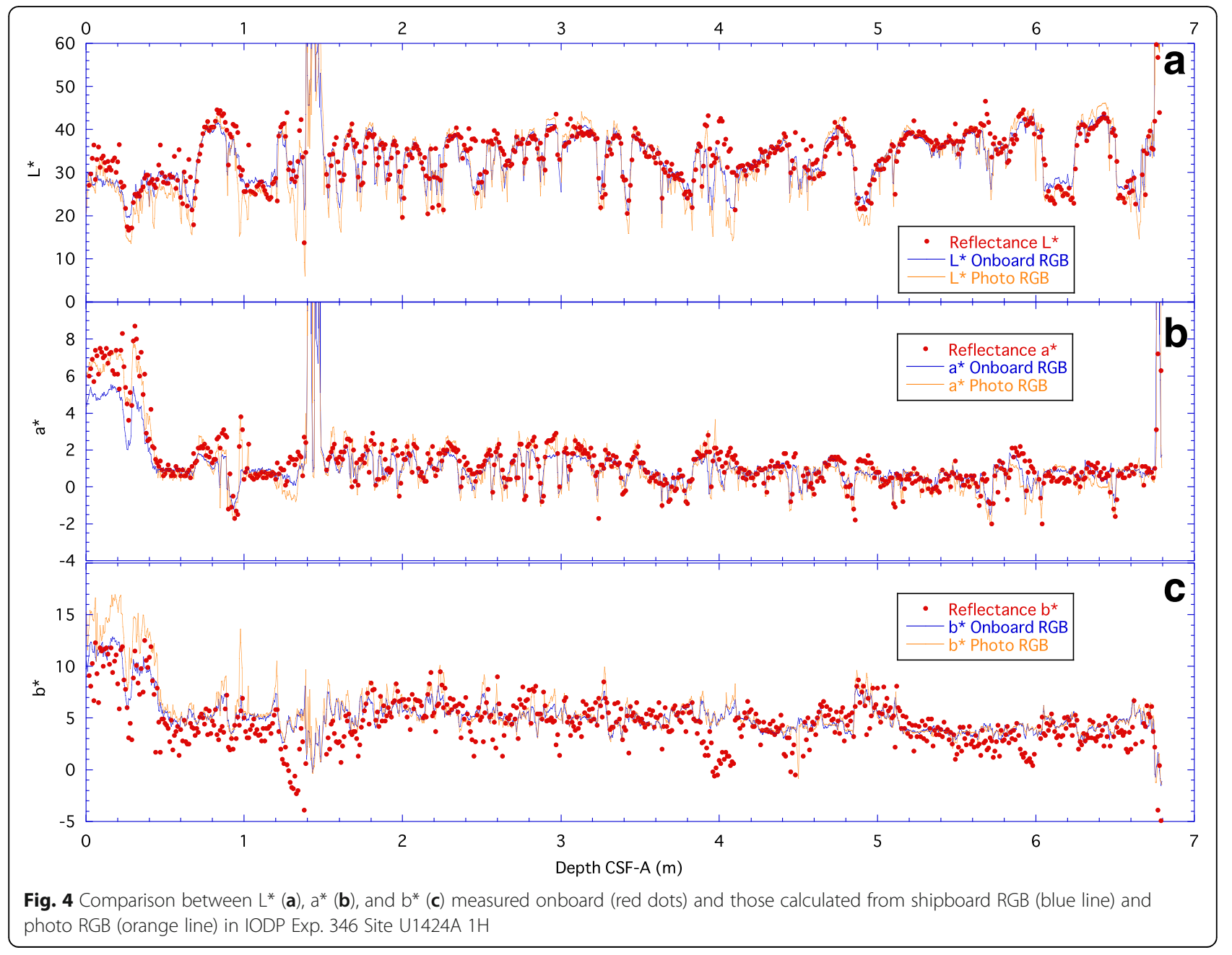

$$
\frac{R G B_{I R}}{255}=a+(1-a)\left(\frac{R G B_{K C C}}{255}\right)^{\gamma}
$$

where bias factors $a$ are set as to $\mathrm{RGB}_{\mathrm{JR}}$ be 255 when $\mathrm{RGB}_{\mathrm{KCC}}$ is 255 . The bias factors $a$ are 0.0849 , 0.080895 , and 0.080709 for R, G, and B, respectively, while the power terms $\gamma$ are 1.6572, 1.6212, and 1.5914 for R, G, and B, respectively (Fig. $7 \mathrm{a}-\mathrm{c}$ ).

Tristimulus $\mathrm{XYZ}$ are principally consistent between JR and KCC, but transparent film used in KCC was SaranWrap $^{\text {Tw }}$ while GladWrap ${ }^{\text {Tw }}$ was used on JR. Therefore, we assumed that small bias factors have to be added to or subtracted from XYZ measured in KCC to match to those on JR such as

$$
X Y Z_{J R}=X Y Z_{K C C}+b
$$

The best estimates of this bias factors $b$ are -5.1763 , -5.6081 , and -5.7142 for $X, Y$, and $Z$, respectively (Fig. $7 \mathrm{~d}-\mathrm{f}$ ). Negative bias factors suggest stronger surface reflection of SaranWrap ${ }^{\text {tix }}$ than that of GladWrap ${ }^{\text {rix }}$.

\section{Results and discussions \\ Overview of patched splices U1422}

Fourteen disturbed intervals were patched (Additional file 8). The total length of the revised spliced sequence was $0.057 \mathrm{~m}$ shorter than the original shipboard splice at 72.21 m CCSF-D.

\section{U1423}

Fifteen disturbed intervals were patched (Additional file 8 ). The total length of the revised spliced sequence was $0.584 \mathrm{~m}$ longer than the original shipboard splice at 132.83 m CCSF-D.

\section{U1424}

Nine disturbed intervals were patched (Additional file 8). The total length of the revised spliced sequence was $1.310 \mathrm{~m}$ longer than the original shipboard splice at 83.76 m CCSF-D. 


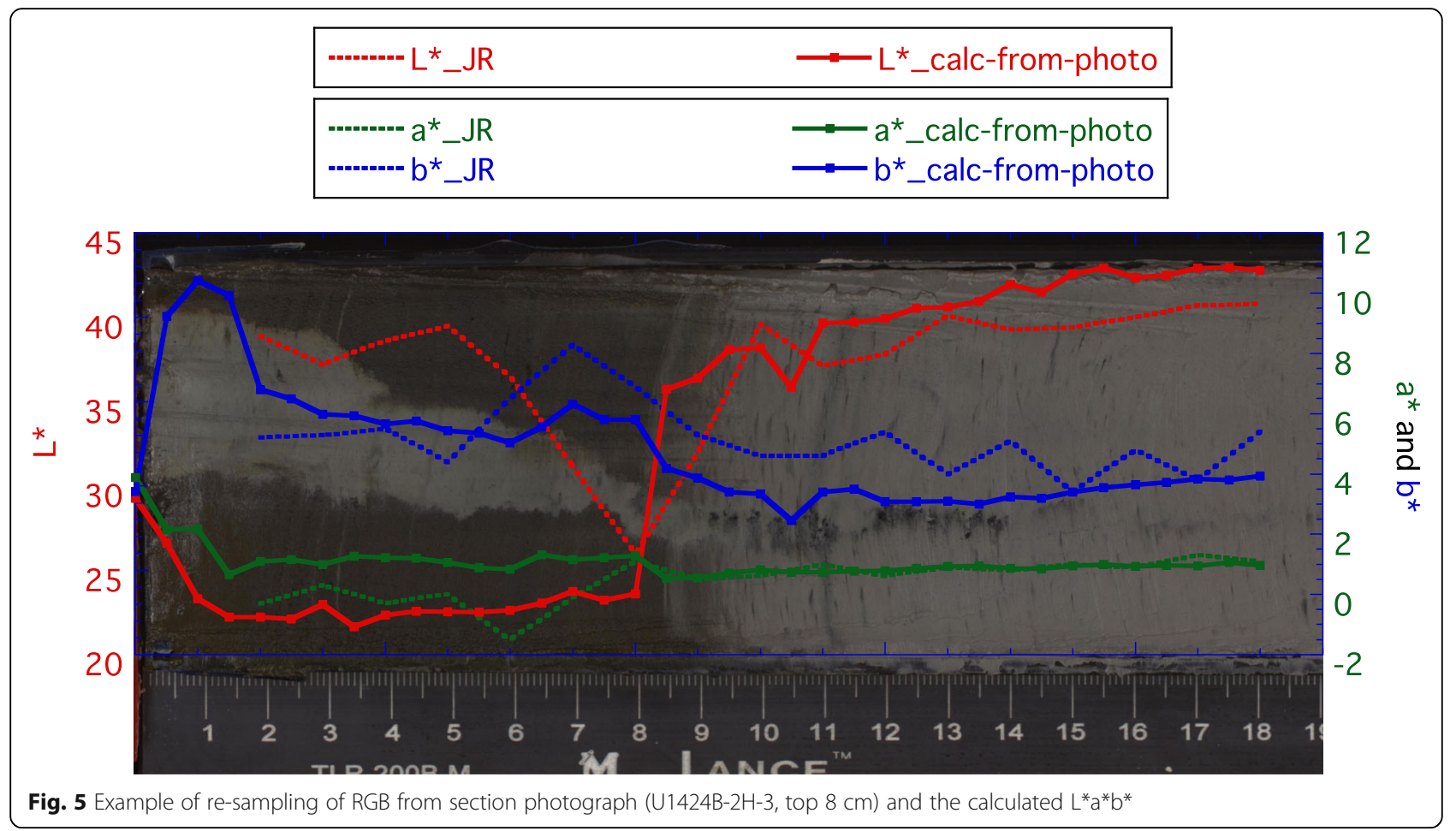

\section{U1425}

Twelve disturbed intervals were patched (Additional file 8 ). The total length of the revised spliced sequence was $0.827 \mathrm{~m}$ longer than the original shipboard splice at 320.86 m CCSF-D.

\section{U1426}

Five disturbed intervals were patched (Additional file 8). The total length of the revised spliced sequence was $4.212 \mathrm{~m}$ longer than the original shipboard splice at 105.95 m CCSF-D.

\section{U1427}

Thirteen disturbed intervals were patched (Additional file 8 ). The total length of the revised spliced sequence was $11.753 \mathrm{~m}$ longer than the original shipboard splice at $257.95 \mathrm{~m}$ CCSF-D.

\section{U1430}

Seven disturbed intervals recognized below $96.15 \mathrm{~m}$ CCSF-D were patched (Additional file 8). The total length of the revised spliced sequence was $1.071 \mathrm{~m}$ shorter than the original shipboard splice at 257.19 m CCSF-D.

\section{Potential utilities of perfectly continuous stratigraphic records}

Sediment sequences characterized by dark-light color cycles exhibit similar patterns of color banding (Fig. 2). After correction, each core-section is nearly continuous such that correlation among these sites using their color banding patterns allows reasonably isochronous horizons to be studied across wide regions of the Japan Sea over millennial time scales (Tada 1994; Tada et al. 1999; Tada et al. 2018). Combination of the reliably continuous stratigraphy at each site and its correlation to the reference site such as U1424 (Tada et al. 2018) enabled more precise tuning age construction at other drilled sites in the Japan Sea.

After inter-site correlations, differences in linear sedimentation rates, GRA densities, and other oceanographic and climatological variability and distribution can be examined for any combination of depth, latitudinal, and longitudinal transects. Further correlation between these dark-light banding sites and Site U1427 with no clear dark-light banding using other correlation tools such as tephrochronology would enable us to examine how the shallower sites such as U1427 respond to millennial-scale climate and oceanographic variability exhibited as dark-light cycles observed at sites with larger water depth (Sagawa et al. 2018).

\section{Maintenance of revised splice records}

Perfectly continuous physical properties' data such as GRA, MS, NGR, RGB, and RSC are summarized in Microsoft Excel books and provided here as Additional file 10: Table S1, Additional file 11: Table S2, Additional file 12: Table S3, Additional file 13: Table S4, Additional file 14: Table S5, Additional file 15: Table S6, 


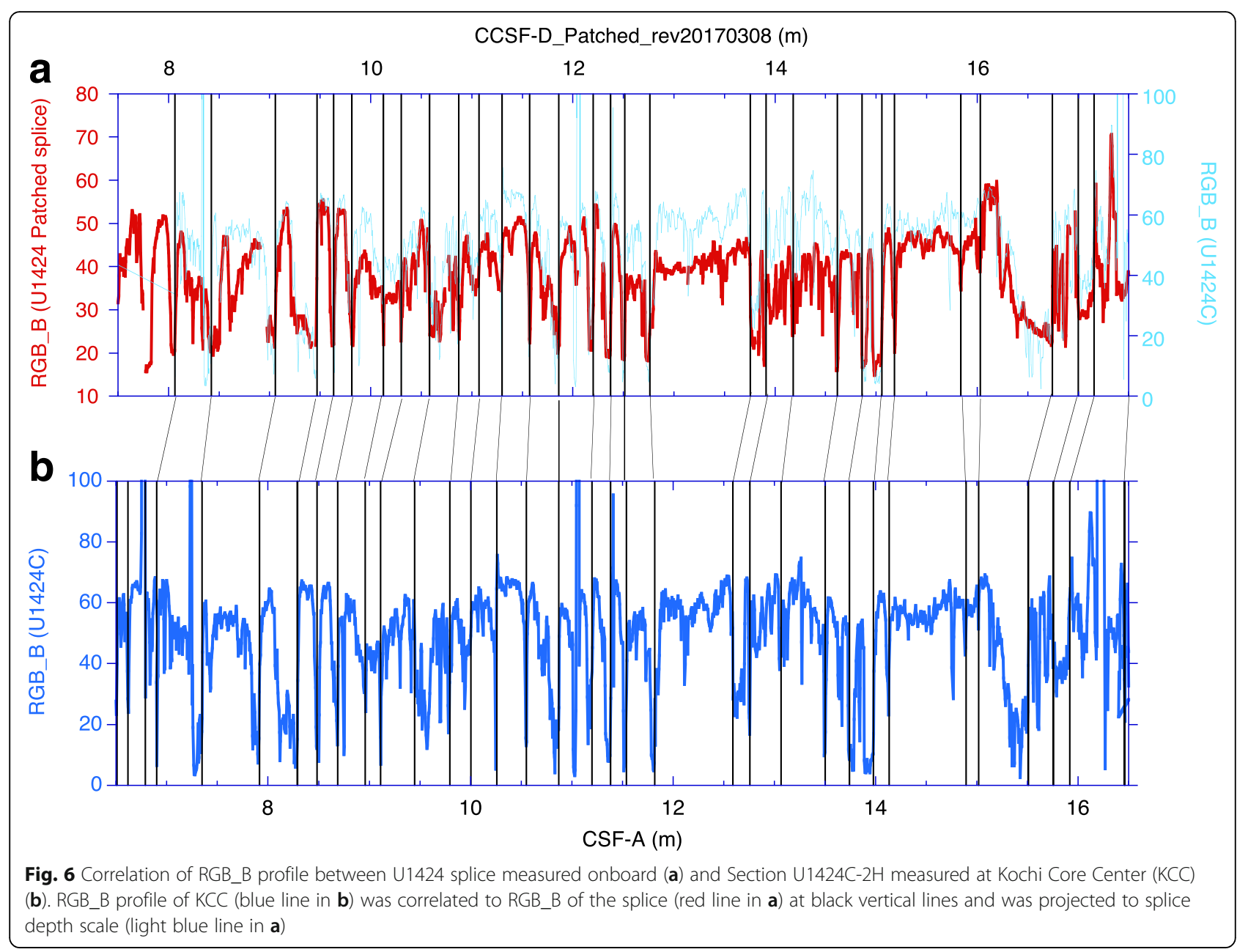

and Additional file 16: Table S7 for further research usage. Microsoft Excel workbooks which automate the calculation of the newly patched depth are also available as Additional file 17: Table S8, Additional file 18: Table S9, Additional file 19: Table S10, Additional file 20: Table S11, Additional file 21: Table S12, Additional file 22: Table S13, and Additional file 23: Table S14. These tables enabled the users to access, examine, and utilize our revised stratigraphic frameworks for the most of the sediment cores collected in the Japan Sea during this expedition. However, the users of these information should notice that the depth scale calculation for the interval out of splice is not necessarily consistent to the spliced section because perfect correlation among holes using dark-light color cycle has not been conducted. The users should check the patched depth on the spliced section corresponding to the horizon out of splice.

Since our policy for the revision of stratigraphic splice is traceability, we put the date of revision to our revised depth scale such as $m$ CCSF-D_Patched_revYYYYMM DD. This means that we are always ready for (potential) further revision of stratigraphic sequences and provide revised "patch" tables to improve the stratigraphy of the drilled cores collected during Exp. 346.

\section{Conclusions}

After extensive efforts for improvement of sediment sequences drilled during IODP Exp. 346, nearly perfectly continuous sediment columns and physical property records for Sites U1422-U1427 and U1430 over the Pleistocene have been established. Stratigraphic revisions were also achieved for Plio-Miocene intervals at Sites U1425 and U1430. All the "patching" processes were clearly demonstrated in patch tables in this study to keep compatibility between depth scales of the original and revised splices. Revised depth scales and patched continuous physical property records are also available as additional file tables (Additional file 10: Table S1; Additional file 11: Table S2; Additional file 12: Table S3; Additional file 13: Table S4; Additional file 14: Table S5; Additional file 15: Table S6; Additional file 16: Table S7). Therefore, the users can access, examine, and utilize our 

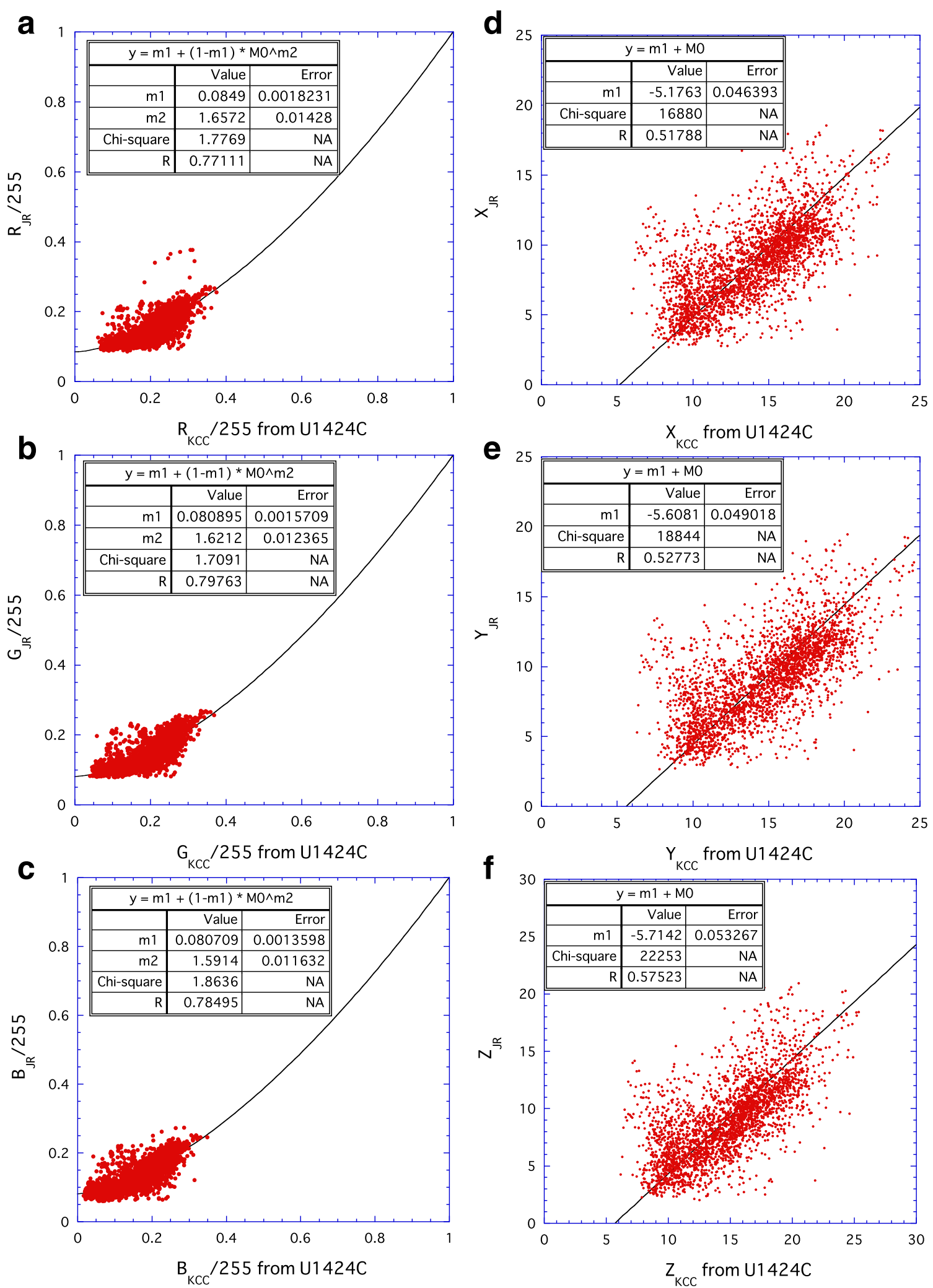

Fig. 7 Relationships between shipboard R (a), G (b), and B (c) and those measured at Kochi Core Center (KCC) and between shipboard X $(\mathbf{d}), Y(\mathbf{e})$, and $Z(\mathbf{f})$ and those measured at KCC 
revised stratigraphic frameworks. Continuous sedimentary records are exceedingly useful for inter-site correlation and enable the examination of the spatial and temporal distribution of material fluxes across wide areas of the Japan Sea for the entire Pleistocene. The continuous record established at these sites will allow a much more detailed understanding of the long-term variability in East Asian paleoclimate and North Pacific oceanography.

\section{Additional files}

Additional file 1: Figure S1. Graphic representations of inter-hole correlations for IODP Exp. 346 Sites U1422. Originally spliced intervals are indicated by blue lines next to core photographs. Disturbed or missing intervals found during visual inspection are indicated by blue broken lines. These disturbed or missing intervals were amended by the corresponding undisturbed "patch" intervals indicated by pink lines. (PDF 1908 kb)

Additional file 2: Figure S2. Graphic representations of inter-hole correlations for IODP Exp. 346 Sites U1423. Originally spliced intervals are indicated by blue lines next to core photographs. Disturbed or missing intervals found during visual inspection are indicated by blue broken lines. These disturbed or missing intervals were amended by the corresponding undisturbed "patch" intervals indicated by pink lines. (PDF 1469 kb)

Additional file 3: Figure S3. Graphic representations of inter-hole correlations for IODP Exp. 346 Sites U1424. Originally spliced intervals are indicated by blue lines next to core photographs. Disturbed or missing intervals found during visual inspection are indicated by blue broken lines. These disturbed or missing intervals were amended by the corresponding undisturbed "patch" intervals indicated by pink lines. (PDF 1806 kb)

Additional file 4: Figure S4. Graphic representations of inter-hole correlations for IODP Exp. 346 Sites U1425. Originally spliced intervals are indicated by blue lines next to core photographs. Disturbed or missing intervals found during visual inspection are indicated by blue broken lines. These disturbed or missing intervals were amended by the corresponding undisturbed "patch" intervals indicated by pink lines. (PDF 8638 kb)

Additional file 5: Figure S5. Graphic representations of inter-hole correlations for IODP Exp. 346 Sites U1426. Originally spliced intervals are indicated by blue lines next to core photographs. Disturbed or missing intervals found during visual inspection are indicated by blue broken lines. These disturbed or missing intervals were amended by the corresponding undisturbed "patch" intervals indicated by pink lines. (PDF 1853 kb)

Additional file 6: Figure S6. Graphic representations of inter-hole correlations for IODP Exp. 346 Sites U1427. Originally spliced intervals are indicated by blue lines next to core photographs. Disturbed or missing intervals found during visual inspection are indicated by blue broken lines. These disturbed or missing intervals were amended by the corresponding undisturbed "patch" intervals indicated by pink lines. (PDF $13721 \mathrm{~kb}$ )

Additional file 7: Figure S7. Graphic representations of inter-hole correlations for IODP Exp. 346 Sites U1430. Originally spliced intervals are indicated by blue lines next to core photographs. Disturbed or missing intervals found during visual inspection are indicated by blue broken lines. These disturbed or missing intervals were amended by the corresponding undisturbed "patch" intervals indicated by pink lines. (PDF $9896 \mathrm{~kb}$ )

Additional file 8: Patch tables for IODP Exp. 346 Sites U1422-U1427 and U1430. (XLSX $97 \mathrm{~kb}$ )

Additional file 9: Revised splice interval tables for IODP Exp. 346 Sites U1422-U1427 and U1430. (XLSX 137 kb)

Additional file 10: Table S1. Physical properties such as MS, GRA, NGR, RGB, and RSC for U1422. Revised depth scale version is CCSF-
D_Patched_rev20150416. L*a*b* values calculated from RGB are also given. (XLSX 5620 kb)

Additional file 11: Table S2. Physical properties such as MS, GRA, NGR, RGB, and RSC for U1423. Revised depth scale version is CCSFD_Patched_rev20150416. L*a*b* values calculated from RGB are also given. (XLSX 6509 kb)

Additional file 12: Table S3. Physical properties such as MS, GRA, NGR, RGB, and RSC for U1424. Revised depth scale version is CCSFD_Patched_rev20170308. L*a*b* values calculated from RGB are also given. (XLSX 4497 kb)

Additional file 13: Table S4. Physical properties such as MS, GRA, NGR, RGB, and RSC for U1425. Revised depth scale version is CCSFD_Patched_rev20170309. L*a*b* values calculated from RGB are also given. (XLSX 13643 kb)

Additional file 14: Table S5. Physical properties such as MS, GRA, NGR, RGB, and RSC for U1426. Revised depth scale version is CCSFD_Patched_rev20150519. L*a*b* values calculated from RGB are also given. (XLSX 8648 kb)

Additional file 15: Table S6. Physical properties such as MS, GRA, NGR, RGB, and RSC for U1427. Revised depth scale version is CCSFD Patched_rev20170310. L*a*b* values calculated from $R G B$ are also given. (XLSX 11638 kb)

Additional file 16: Table S7. Physical properties such as MS, GRA, NGR, RGB, and RSC for U1430. Revised depth scale version is CCSFD_Patched_rev20160113. L*a*b* values calculated from RGB are also given. (XLSX $9048 \mathrm{~kb}$ )

Additional file 17: Table S8. Calculation worksheet for U1422 revised depth scale (CCSF-D_Patched_rev20150416). (XLSX 98 kb)

Additional file 18: Table S9. Calculation worksheet for U1423 revised depth scale (CCSF-D_Patched_rev20150416). (XLSX 96 kb)

Additional file 19: Table S10. Calculation worksheet for U1424 revised depth scale (CCSF-D_Patched_rev20170308). (XLSX 87 kb)

Additional file 20: Table S11. Calculation worksheet for U1425 revised depth scale (CCSF-D_Patched_rev20170309). (XLSX 141 kb)

Additional file 21: Table S12. Calculation worksheet for U1426 revised depth scale (CCSF-D_Patched_rev20150519). (XLSX 117 kb)

Additional file 22: Table S13. Calculation worksheet for U1427 revised depth scale (CCSF-D_Patched_rev20170310). (XLSX 172 kb)

Additional file 23: Table S14. Calculation worksheet for U1430 revised depth scale (CCSF-D_Patched_rev20160113). (XLSX 110 kb)

Additional file 24: Figure S8. Full size version of Figure 2. (PDF 21887 kb)

\section{Abbreviations}

Exp.: Expedition; GRA: Gamma-ray attenuation density; IODP: Integrated Ocean Drilling Program; KCC: Kochi Core Center; LIMS: Laboratory Information Management System; MS: Magnetic susceptibility; NGR: Natural gamma-ray radiation; ODP: Ocean Drilling Program; OSL: Optically stimulated luminescence; RGB: Red-green-blue channel of digital image; RSC: Reflectance spectroscopy and colorimetry; TWC: Tsushima Warm Current

\section{Acknowledgements}

We would like to express our sincere thanks to all of the scientists, technicians, and crews of DN JOIDES resolution during IODP Expedition 346. This work was financially supported by IODP Exp. 346 After Cruise Research Program, JAMSTEC.

\section{Funding}

Not applicable.

\section{Authors' contributions}

TI supervised each stratigraphic patching task, summarized the patch tables, calibrated and patched physical properties, and established the data share websites for all the drilled sites. RT and KI also supervised all the course of stratigraphic revisions and advised for improvement. TS mainly worked for the stratigraphic revision and figure drawing for U1427. AK and AS compiled core photographs and revised stratigraphy for U1424, U1425, U1426, and 
U1430 mainly for Pleistocene intervals. SK worked for the Plio-Miocene intervals for U1425 and U1430. SL exclusively compiled the core photographs and revised the stratigraphy for U1422 and U1423. All authors read and approved the final manuscript.

\section{Authors' information}

RT was a co-chief scientist, TI was a stratigraphic correlator, and Kl, TS, and AK were sedimentologists onboard for Exp. 346. RT is a supervisor for AK, AS, and SK in Graduate School of Science, University of Tokyo. TI is a supervisor for SL in Graduate School of Environmental Science, Hokkaido University.

\section{Competing interests}

The authors declare that they have no competing interest.

\section{Publisher's Note}

Springer Nature remains neutral with regard to jurisdictional claims in published maps and institutional affiliations.

\section{Author details}

${ }^{1}$ Faculty of Environmental Earth Science, Hokkaido University, N10-W5 Kita-ku, Sapporo 060-0810, Japan. ${ }^{2}$ Graduate School of Science, the University of Tokyo, 7-3-1 Hongo, Bunkyo-ku, Tokyo 113-0033, Japan. ${ }^{3}$ Geological Survey of Japan, National Institute of Advanced Industrial Science and Technology, Tsukuba Central 7, 1-1-1 Higashi, Tsukuba, Ibaraki 305-8567, Japan. ${ }^{4}$ Institute of Science and Engineering, Kanazawa University, Kakuma-machi, Kanazawa, Ishikawa 920-1192, Japan. ${ }^{5}$ Graduate School of Environmental Science, Hokkaido University, N10-W5 Kita-ku, Sapporo 060-0810, Japan

Received: 5 October 2017 Accepted: 21 February 2018

\section{Published online: 19 April 2018}

\section{References}

Channell JET, Guyodo Y (2004) The Matuyama Chronozone at ODP 982 (Rockall Bank): evidence for decimeter-scale magnetization lock-in depths. In: Channell JET, Kent DV, Lowrie W, Meert J (eds) Timescales of the internal geomagnetic field, vol 145. AGU Geophysical Monograph, Washington, D. C., pp 205-219.

CIE (2004) Colorimetry, vol 15, 3rd edn. Commission internationale de l'Eclairage, CIE Central Bureau, Vienna, p 72

Doyle P, Bennett MR (eds) (1998) Unlocking the stratigraphic record-advances in modern stratigraphy. Wiley, Chichester.

Ebner M (2007) Color Constancy. Wiley, Chichester.

Emeis K-C et al (1996) Proceedings of the ocean drilling. Program, initial reports, vol 160. Ocean Drill. Program, College Station.

Evans HF, Westerhold T, Channell JET (2004) ODP Site 1092: revised composite depth section has implications for Upper Miocene 'cryptochrons'. Geophys J Int 156:195-99. https://doi.org/10.1111/j.1365-246X.2003.02189.x.

Gamo T, Nakayama N, Takahata N, Sano Y, Zhang J, Yamazaki E, Taniyasu S, Yamashita N (2014) The sea of Japan and its unique chemistry revealed by time-series observations over the last 30 years. Monogr Environ Earth Planets 2(1):1-22. https://doi.org/10.5047/meep.2014.00201.0001.

Gersonde R, Hodell DA, Blum P, Shipboard Scientific Party (1999) Proc. ODP, Init. Repts, vol 177. Ocean Drilling Program, Texas A \& M University, USA, pp 1-82.

Hase H, Yoon JH, Koterayama W (1999) The current structure of the Tsushima Warm Current along the Japanese Coast. J Oceanogr 55(2):217-235. https:// doi.org/10.1023/A:1007894030095.

International Electrotechnical Commission (1999) IEC 61966-2-1:1999.

Irino T, Tada R (2000) Quantification of aeolian dust (Kosa) contribution to the Japan Sea sediments and its variation during the last $200 \mathrm{ky}$. Geochem J 34(1):59-93.

Irino T, Tada R (2002) High resolution reconstruction of variation in aeolian dust (Kosa) deposition at ODP site 797, the Japan Sea, during the last 200 ky. Glob Planet Chang 35:107-120.

Jansen E, Raymo ME, Blum P et al (1996). Proc ODP, Init. Repts., 162: College Station, TX (Ocean Drilling Program). https://doi.org/10.2973/odp.proc.ir.162.1996.

Khélifi N, Sarnthein M, Naafs BDA (2012) Technical note: Late Pliocene age control and composite depths at ODP Site 982, revisited. Climate of the Past 8:79-87. https://doi.org/10.5194/cp-8-79-2012.

Lourens LJ (2004) Revised tuning of Ocean Drilling Program Site 964 and KC01B (Mediterranean) and implications for the d180, tephra, calcareous nannofossil, and geomagnetic reversal chronologies of the past $1.1 \mathrm{Myr}$. Paleoceanography 19:PA3010. https://doi.org/10.1029/2003PA000997.

Lawrence KT, Bailey I, Raymo ME (2013) Re-evaluation of the age model for North Atlantic Ocean Site 982 - arguments for a return to the original chronology. Climate of the Past 9:2391-97. https://doi.org/10.5194/cp-9-2391-2013.

Lyle, M., Raffi, I., Pälike, H., Nishi, H., Gamage, K., Klaus, A., and the Expedition 320/ 321 Scientists (2009) Pacific equatorial transect. IODP Prel Rept, 321. https:// doi.org/10.2204/ iodp.pr.321.2009.

Ruddiman WF, Cameron D, Clement BM (1987) Sediment disturbance and correlation of offset holes drilled with the hydraulic piston corer-Leg 94 Initial Rep Deep Sea Drill Proj 94:615-634.

Sagawa T, Nagahashi Y, Satoguchi Y, Holbourn A, Itaki T, Gallagher SJ, SaavedraPellitero M, Ikehara K, Irino T, Tada R (2018) Integrated tephrostratigraphy and stable isotope stratigraphy in the Japan Sea and East China Sea using IODP Sites U1426, U1427 and U1429, Expedition 346 Asian Monsoon. Prog Earth Planet Sci in press. https://doi.org/10.1186/s40645-018-0168-7.

Sakamoto T, Janecek T, Emeis K-C (1998) Continuous sedimentary sequences from the eastern Mediterranean Sea: composite depth sections. Proc. Ocean Drill. Program, Sci Results 160:37-59.

Tada R (1994) Paleoceanographic evolution of the Japan Sea. Palaeogeogr. Palaeoclimatol Palaeoecol 108(3-4):487-508. https://doi.org/10.1016/00310182(94)90248-8.

Tada R, Irino T, Ikehara K, Karasuda A, Sugisaki S, Xuan C, Sagawa T, Itaki T, Kubota Y, Lu S, Seki A, Murray RW, Alvarez-Zarikian C, Anderson, Jr WT, Bassetti M-A, Brace BJ, Clemens SC, da Costa Gurgel MH, Dickens GR, Dunlea AG, Gallagher SJ, Giosan L, Henderson ACG, Holbourn AE, Kinsley CW, Lee G-S, Lee K-E Lofi J, Lopes CICD, Saavedra Pellitero M, Peterson LC, Singh RK, Toucanne S, Wan S, Zheng H, Ziegler M (2018) High-resolution and -precision correlation of dark and light layers in the quaternary hemipelagic sediments of the Japan Sea recovered during IODP Expedition 346. Prog Earth Planet Sci in press.

Tada R, Irino T, Koizumi I (1999) Land-ocean linkages over orbital and millennial timescales recorded in late quaternary sediments of the Japan Sea. Paleoceanography 14(2):236-247 https://doi.org/10.1029/1998PA900016.

Tada R, Murray RW, Alvarez Zarikian CA, and the Expedition 346 Scientists (2015) Proceedings of Integrated Ocean Drilling Program. IODP volume 346. College Station (Integrated Ocean Drilling Program). https://doi.org/10.2204/iodp.proc. 346.101.

Westerhold, T., Röhl, U., Wilkens, R., Pälike, H., Lyle, M., Jones, T.D., Bown, P., Moore, T., Kamikuri, S., Acton, G., Ohneiser, C., Yamamoto, Y., Richter, C., Fitch, P., Scher, H., Liebrand, D., and the Expedition 320/321 Scientists (2012) Revised composite depth scales and integration of IODP Sites U1331-U1334 and ODP Sites 1218-1220. In Pälike, H., Lyle, M., Nishi, H., Raffi, I., Gamage, K., Klaus, A., and the Expedition 320/321 Scientists, Proc IODP, 320/321: https:// doi.org/10.2204/iodp.proc.320321.201.2012 Tokyo (Integrated Ocean Drilling Program Management International, Inc.) 